\title{
Improvisational Theater for Information Systems: An Agile, Experience-Based, Prototyping Technique
}

\author{
Martin Mahaux and Patrick Heymans \\ PReCISE Research Centre, Faculty of Computer Science, University of Namur \\ Grandgagnage, 21, 5000 Namur, Belgium \\ \{martin.mahaux, patrick.heymans\}@fundp.ac.be
}

\begin{abstract}
Collaborative creativity is key to innovative software development. It is however not easy to master, and few techniques have focused on those aspects. Games have recently started to receive serious attention to fill this gap. In this context, this tutorial proposes participants a fun and refreshing learning moment. Through actually playing improvisational theatre (improv) games in group, participants will learn new ways to generate scenarios through a collaborative, cheap, rapid, experience-based, design technique.
\end{abstract}

\section{Introduction}

According to many commentators, creativity is the new key economic activity. This holds for the development of Information Systems (IS) as much as in many other sectors of the economy, and so we must look for ways of bringing more creativity into IS development [1]. Developing IS can be seen as a fundamentally collaborative and creative process, from discovering requirements until development, through architecture. While these concerns are still largely considered in isolation, the success of agile paradigms forces us to see them as a whole, putting an even stronger emphasis on collaboration and creativity. While collaboration and creativity may yield wonderful results, they remain difficult to achieve. IS engineers and researchers are currently lacking skills in these areas, and training is hard to find. Moreover, adapted collaborative creativity techniques are lacking too. This mini-tutorial intends to show participants how to fill this gap by building upon results on using improv for design (e.g. 3445677). These show that improv supports team-based innovation. To achieve this, it provides techniques for improving communication between stakeholders, increasing mutual understanding as well as open-mindedness, creativity, empathy, self and mutual confidence, agility... It also helps generating and testing ideas, by exploiting the notion of story and story-telling. We argue that this cheap and rapid storymaking technique can effectively be considered an experience-based design technique: the focus is on the experience around the product, not on the product. By exaggerating the characteristics of group creativity (emergence, intersubjectivity, unpredictability, communication [8]), improv eases its understanding. It also 
provides a framework for different types of creativity: exploration, combination, transformation. Finally, improv offers a more collaborative and positive model for conflict resolution, in that it uses conflict as the source of creativity.

\section{Outline}

During the introduction (10'), we first briefly define creativity, motivate the need for it, and then expose some theoretical bases that establish the link between improv and creativity. Then comes an awareness exercise (10') to raise group awareness and open the participants' mind for the remainder of the session. The warm-up exercise (10') will help people remove their tie or sweat-shirt, and get rid of some of their auto-censorship reflexes. We can now switch to the main activity, the creative session (60'). We will pretend that we are a group of stakeholders (including problem owners, developers, experts) willing to invent a new software product. We will use guided improvisations as an experience-based technique, inventing user stories on the fly, and commenting them in order to determine what our product should or should not do. So, while some play out scenarios they invent on the fly guided by the improv' coach, others watch and comment, take note of ideas, scenarios, requirements, feasibility problems and alternative solutions. Then we all debrief.

This work is sponsored by the Walloon Region under the European Regional Development Fund (ERDF).

\section{References}

1. Jones, S., Lynch, P., Maiden, N.A.M., Lindstaedt, S.N.: Use and influence of creative ideas and requirements for a work-integrated learning system, pp. 289-294 (2008)

2. Mahaux, M., Mavin, A., Heymans, P.: Choose Your Creativity: Why and How Creativity in Requirements Engineering Means Different Things to Different People. In: Regnell, B., Damian, D. (eds.) REFSQ 2012. LNCS, vol. 7195, pp. 101-116. Springer, Heidelberg (2012)

3. Brandt, E., Grunnet, C.: Evoking the future: Drama and props in user centered design. In: Proceedings of Participatory Design Conference (PDC 2000), pp. 11-20 (2000)

4. Iacucci, G., Kuutti, K.: Everyday life as a stage in creating and performing scenarios for wireless devices. Personal and Ubiquitous Computing 6(4), 299-306 (2002)

5. Sorby, I., Melby, L., Seland, G.: Using scenarios and drama improvisation for identifying and analysing requirements for mobile electronic patient records. In: Requirements Engineering for Sociotechnical Systems, pp. 266-283.

6. Boess, S.: Making role playing work in design. In: Design and Semantics of Form and Movement, p. 117 (2006)

7. Mahaux, M., Maiden, N.A.M.: Theater improvisers know the requirements game. IEEE Software 25(5), 68-69 (2008)

8. Sawyer, R.K.: Group Creativity: Music, Theater, Collaboration. LEA (January 2009) 